\title{
Ethacridine Induces Apoptosis and Differentiation in Thyroid Cancer Cells In Vitro
}

\author{
TUNG-SUN HUANG ${ }^{1,2}$, JIE-JEN LEE ${ }^{2}$, YING-SYUAN LI ${ }^{2,3}$ and SHIH-PING CHENG ${ }^{2,3,4}$ \\ ${ }^{1}$ Institute of Traditional Medicine, School of Medicine, National Yang-Ming University, Taipei, Taiwan, R.O.C.; \\ ${ }^{2}$ Department of Surgery, MacKay Memorial Hospital and Mackay Medical College, Taipei, Taiwan, R.O.C.; \\ ${ }^{3}$ Department of Medical Research, MacKay Memorial Hospital, Taipei, Taiwan, R.O.C.; \\ ${ }^{4}$ Department of Pharmacology, School of Medicine, College of Medicine, \\ Taipei Medical University, Taipei, Taiwan, R.O.C.
}

\begin{abstract}
Background/Aim: Ethacridine is used as a topical antiseptic as well as for second-trimester abortion. Recent studies showed that ethacridine is an inhibitor of poly(ADPribose) glycohydrolase (PARG) and an activator of the transcriptional coactivator with PDZ-binding motif (TAZ). This study examined the effects of ethacridine on thyroid cancer cells. Materials and Methods: Thyroid cancer cell lines (FTC133 and SW1736) and thyroid follicular epithelial cells (Nthy-ori 3-1) were treated with ethacridine. Viability, clonogenicity, cell-cycle distribution, and apoptosis were evaluated. The expression of thyroid differentiation markers (TTF-1, PAX8, and NIS) was determined by real-time PCR Results: Ethacridine suppressed cell growth and clonogenic ability of thyroid cancer cells in a time-and dose-dependent manner $(p<0.001)$. No cell-cycle arrest was found, but ethacridine dose-dependently induced apoptosis of thyroid cancer cells $(p<0.001)$. The PAX8 and NIS expressions were significantly increased in SW1736 (3.41-fold and 1.53-fold, respectively) and Nthy-ori 3-1 cells (2.73-fold and 4.12-fold, respectively). Conclusion: Ethacridine elicits apoptotic cell death in thyroid cancer cells and promotes differentiation in a subset of thyroid follicular cells.
\end{abstract}

The incidence rate of thyroid cancer has been rising worldwide. It has been argued that the increased incidence is likely due to the increase in the detection of subclinical disease. However, a recent analysis of the Surveillance, Epidemiology, and End Results (SEER) database showed an annual 3\% increase in the overall incidence of thyroid cancer as well as an increase in the thyroid cancer mortality rate for advanced-stage thyroid cancer,

Correspondence to: Shih-Ping Cheng, $\mathrm{MD}, \mathrm{PhD}$, Department of Surgery, MacKay Memorial Hospital 92, Section 2, Chung-Shan North Road, Taipei 10449, Taiwan, R.O.C. Tel: +886 225433535, Fax:+886 227233897, e-mail: surg.mmh@gmail.com

Key Words: Ethacridine, apoptotic cell death, thyroid cancer cells. suggesting a true increase in the occurrence of thyroid cancer (1). Generally, the majority of differentiated thyroid cancer carries an excellent prognosis. Nonetheless, some patients experience locoregional recurrence and/or distant metastasis which may compromise overall survival (2). We previously showed that recurrence is associated with down-regulation of most of the thyroid differentiation genes (3).

Standard therapies for thyroid cancer include surgery and radioactive iodine therapy, while molecularly targeted agents have been developed to prolong progression-free survival in patients who are refractory to radioactive iodine therapy (4). Nonetheless, adverse effects and modest efficacy of currently available agents underline the need for the identification of novel therapeutics. Recently, a high-throughput chemical screen demonstrated that ethacridine, a poly(ADP-ribose) glycohydrolase (PARG) inhibitor, may sensitize ibrutinib in leukemia cells (5). Furthermore, ethacridine is an activator of the transcriptional coactivator with PDZ-binding motif (TAZ), which may direct differentiation of thyroid follicular cells from human embryonic stem cells (6). Ethacridine (trade name Rivanol) is widely used as a topical antiseptic and for the second-trimester abortion (7). It has been shown that treatment with ethacridine augmented the expression of transcription factors thyroid transcription factor-1 (TTF-1, encoded by the NKX2-1 gene) and paired-box gene 8 (PAX8). More importantly, ethacridine greatly amplified the expression of the sodium-iodide symporter (NIS, encoded by the SLC5A5 gene) in embryonic stem cells, which is critical for efficient iodide uptake in thyroid cells (6). Therefore, this study aimed to investigate the effects of ethacridine on thyroid cancer cells, as well as its therapeutic potential in the management of thyroid cancer.

\section{Materials and Methods}

Cell culture and reagents. The human follicular thyroid cancer cell line FTC133 and the immortalized human differentiated thyrocyte cell line Nthy-ori 3-1 were purchased from the European Collection 
FTC133

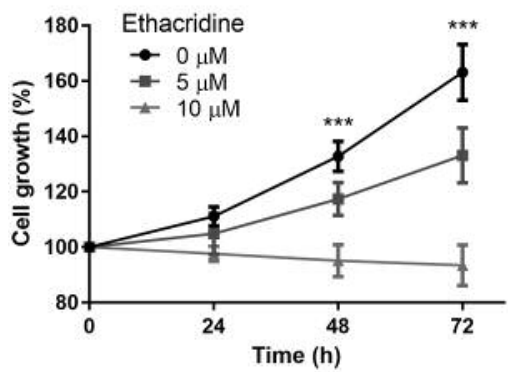

SW1736

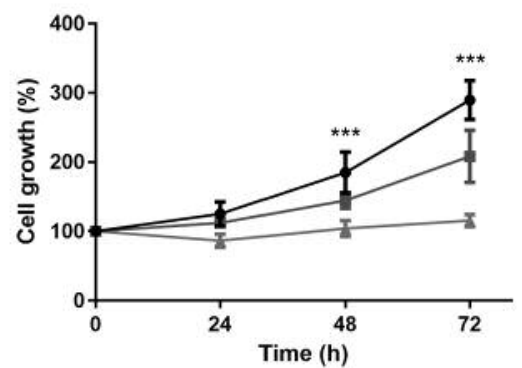

Nthy-ori 3-1

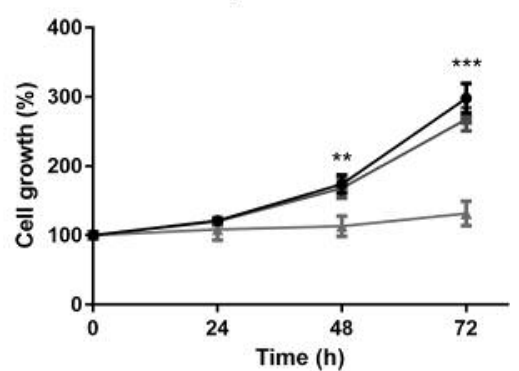

Figure 1. Effects of ethacridine on cell growth. Thyroid cancer cells (FTC133 and SW1736) and thyroid follicular epithelial cells (Nthy-ori 3-1) were treated with ethacridine ( 0 to $10 \mu \mathrm{M}$ ) for 24 to $72 \mathrm{~h}$. Cell viability was determined using the Cell Counting Kit-8 assay. **p<0.01, ***p<0.001 versus control.

of Authenticated Cell Cultures (ECACC; Salisbury, UK). The human anaplastic thyroid cancer cell line SW1736 was obtained from CLS Cell Lines Service GmbH (Eppelheim, Germany). Cells were cultured in RPMI-1640 medium supplemented with $10 \%$ fetal bovine serum (FBS; Gibco, Thermo Fisher Scientific, Waltham, MA, USA) and L-glutamine (2 mM; Sigma-Aldrich, St. Louis, MO, USA) at $37^{\circ} \mathrm{C}$ in a humidified incubator with $5 \% \mathrm{CO}_{2}$. Cell line authenticity was confirmed by DNA short tandem repeat analysis and maintained free of mycoplasma in our laboratory by appropriate control measures (8). Ethacridine was purchased from Abcam, Cambridge, UK (catalog number ab143396).

Cell viability assay. FTC133, SW1736, and Nthy-ori 3-1 cells were seeded in 96-well plates at $1 \times 10^{4}$ cells/well and cultured for $24 \mathrm{~h}$. Subsequently, the cells were treated with increasing concentrations of ethacridine $(0,5$, and $10 \mu \mathrm{M})$ for 24 to $72 \mathrm{~h}$. Cells treated with vehicle (phosphate buffered saline) served as control. Cell viability was determined using the Cell Counting Kit-8 (CCK-8; SigmaAldrich), in which colorimetric readout is proportional to the number of living cells due to the orange formazan produced by live cells. The absorbance was measured with Varioskan Flash (Thermo Fisher Scientific) at a wavelength of $450 \mathrm{~nm}$. The $\mathrm{IC}_{50}$ values defined as the ethacridine concentrations required for $50 \%$ inhibition of cell viability were determined from dose-response curves (9).

Clonogenic assay. For the colony-forming assay, FTC133 or SW1736 thyroid cancer cells were seeded into six-well plates (500 cells/well) in the presence of increasing concentrations of ethacridine $(0,5$, and $10 \mu \mathrm{M})$. After 10 days, colonies were stained with $3 \%$ crystal violet. Colonies containing at least 50 individual cells were counted under a microscope (10).

Cell cycle analysis. Cells were placed in six-well plates $\left(4 \times 10^{5}\right.$ cells/well), synchronized by serum starvation, and then stimulated to enter the cell cycle by the addition of fresh full-growth medium containing different concentrations of ethacridine $(0,5$, and $10 \mu \mathrm{M})$ for 24 to $48 \mathrm{~h}$. Subsequently, cells were harvested and fixed with $70 \%$ ethanol at $4{ }^{\circ} \mathrm{C}$ overnight. Fixed cells were washed and incubated with propidium iodide (PI; $5 \mu \mathrm{g} / \mathrm{ml}$; Sigma-Aldrich). DNA content was analyzed with the BD FACSCalibur flow cytometer (BD Biosciences, San Jose, CA, USA) as previously described (11).
Table I. Forward and reverse primer sequences used in real-time PCR.

\begin{tabular}{lll}
\hline TTF-1 & Forward & 5'-GCC GTA CCA GGA CAC CAT GAG-3' \\
& Reverse & 5'-CAG GTA CTT CTG TTG CTT GAA G-3' \\
PAX8 & Forward & 5'-AAG TCC AGC ATT GCG GCA CA-3' \\
& Reverse & 5'-GAG GGA AGT GCT TAT GGT CC-3' \\
NIS & Forward & 5'-CCC CAG CTC AGG AAT GGA-3' \\
& Reverse & 5'-CGT AAT AGA GAT AGG AGA TGG \\
& & CAT AGA A-3' \\
\multirow{3}{*}{ 3-Actin } & Forward & 5'-TGG CAT TGC CGA CAG GAT-3' \\
& Reverse & 5'-GCT CAG GAG GAG CAA TGA TCT-3' \\
\hline
\end{tabular}

Apoptosis analysis. Cell apoptosis was analyzed using the annexin V-fluorescein isothiocyanate (FITC) apoptosis detection kit (BD Biosciences) in accordance with the manufacturer's protocol (12). Briefly, cells were seeded into six-well plates $\left(4 \times 10^{5}\right.$ cells/well $)$ and grown to confluence overnight. Subsequently, cells were treated with indicated concentrations of ethacridine $(0,5$, and $10 \mu \mathrm{M})$ for 24 to $48 \mathrm{~h}$. Cells were harvested and suspended in the binding buffer supplied by the manufacturer. Following incubation with $5 \mu \mathrm{l}$ of annexin V-FITC and $5 \mu \mathrm{l}$ of PI for $15 \mathrm{~min}$ at room temperature in the dark, the stained cells were analyzed by flow cytometry. After the acquisition of at least 10,000 events, data were analyzed using CellQuest Pro software (BD Biosciences).

Real-time quantitative polymerase chain reaction (PCR). Following treatment with ethacridine $(10 \mu \mathrm{M})$ for $48 \mathrm{~h}$, total cellular RNA was extracted with TRIzol reagent (Thermo Fisher Scientific) and reversetranscribed using SuperScript III Reverse Transcriptase (Thermo Fisher Scientific). Real-time quantitative PCR reactions were performed on a 7500 Fast Real-Time PCR System (Applied Biosystems, Foster City, CA, USA) (13). The PCR conditions were 5 min of initial denaturation at $94^{\circ} \mathrm{C}$, followed by 35 cycles of denaturation at $94^{\circ} \mathrm{C}$ for $15 \mathrm{~s}$, annealing at $55^{\circ} \mathrm{C}$ for $30 \mathrm{~s}$, and extension at $72^{\circ} \mathrm{C}$ for $40 \mathrm{~s}$, and a $2-m i n$ final extension at $72^{\circ} \mathrm{C}$. The primers used in this study are listed in Table I. Fast SYBR Green Master Mix (Thermo Fisher Scientific) was used to detect fluorescence. The expressions of TTF-1, PAX8, and NIS were normalized against the control $\beta$-actin and analyzed using the standard $2^{-\Delta \Delta \mathrm{Ct}}$ method. 

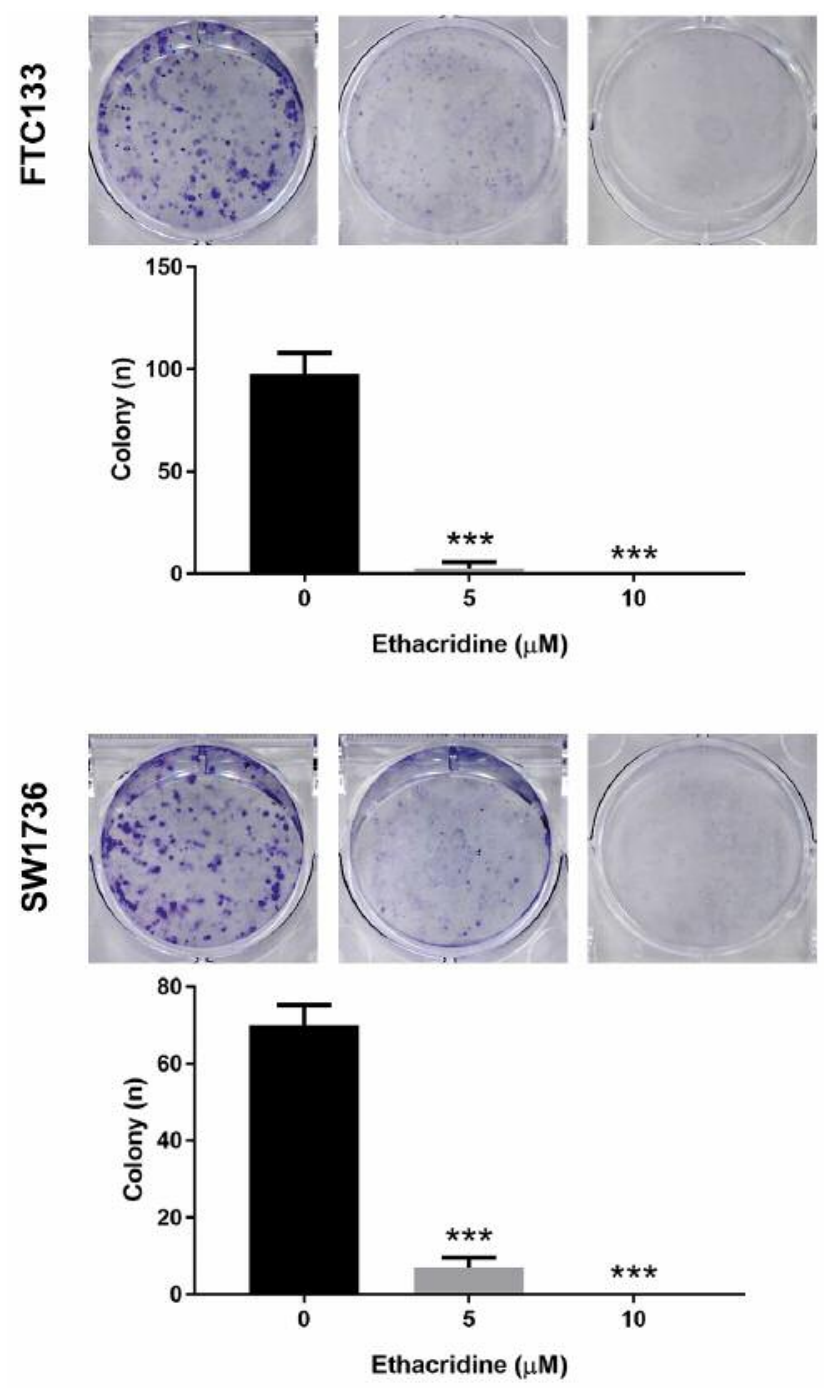

Figure 2. Effects of ethacridine on clonogenicity in thyroid cancer cells. FTC133 and SW1736 cells were treated with ethacridine (0 to $10 \mu \mathrm{M})$ for 10 days. The number of colonies was manually counted. $* * * p<0.001$ versus control.

Statistical analysis. Data were reported as the mean \pm standard error of the mean from at least three independent experiments. Comparisons between two groups were performed using the twotailed Welch's $t$-test (14), while between three or more groups were assessed using the analysis of variance (ANOVA) followed by Holm-Sidak multiple comparisons. Probability values less than 0.05 were considered statistically significant.

\section{Results}

Ethacridine showed a trend to decrease the number of viable cells in thyroid cancer cells. Firstly, we evaluated the effects of ethacridine on cell growth in thyroid cancer and normal thyroid epithelial cells. As shown in Figure 1, cell viability was shown to be reduced, as detected by the Cell Counting Kit- 8 assay, in a time- and dose-dependent manner in three
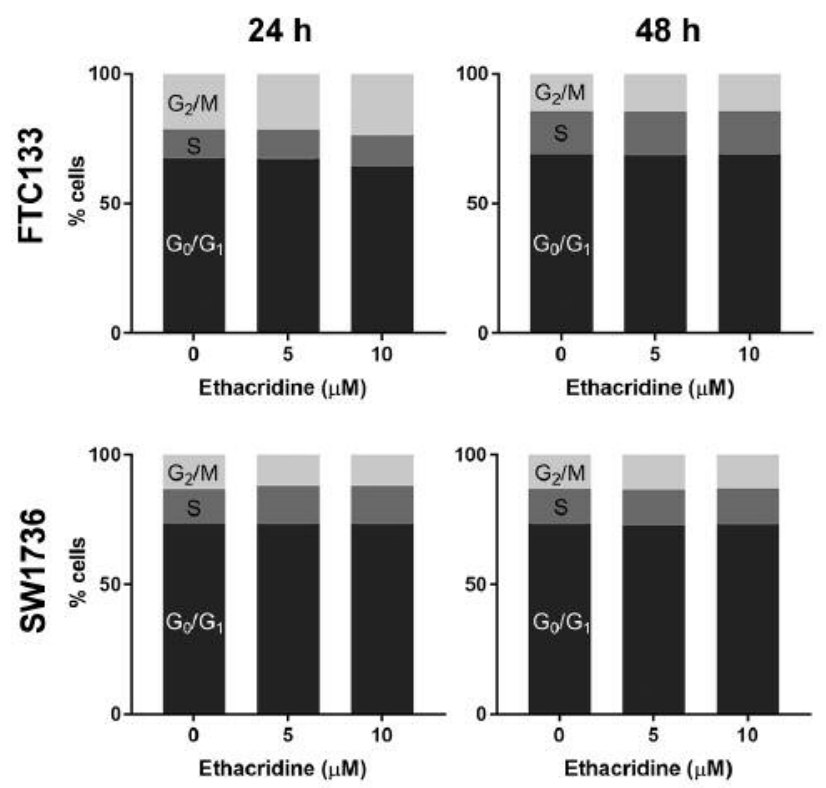

Figure 3. Effects of ethacridine on cell-cycle distribution in thyroid cancer cells. FTC133 and SW1736 cells were treated with ethacridine (0 to $10 \mu \mathrm{M}$ ) for 24 to $48 \mathrm{~h}$. Cell-cycle analysis was performed using flow cytometry.

cell lines we tested. At $72 \mathrm{~h}$, the $\mathrm{IC}_{50}$ value of ethacridine in Nthy-ori $3-1$ cells $(9.43 \pm 1.57 \mu \mathrm{M})$ was marginally lower than that in FTC133 cells $(11.85 \pm 1.75 \mu \mathrm{M}, p=0.09)$, indicating a possibility that the normal epithelial cells were more sensitive to the inhibitory effects of ethacridine. However, the $\mathrm{IC}_{50}$ value in SW1736 cells $(8.96 \pm 0.82 \mu \mathrm{M})$ was similar to that in Nthy-ori 3-1 cells $(p=0.62)$.

Ethacridine inhibited the formation of cell colonies. We further determined the clonogenic ability of cells following the treatment of ethacridine. Clonogenicity is an estimate of the reproductive viability of cancer cells (capacity of a single-cell suspension to produce progeny). It was demonstrated that ethacridine exhibited a strong inhibitory effect on colony formation in thyroid cancer cells (ANOVA $p<0.001$ in both cell lines; Figure 2). In fact, at a concentration of $10 \mu \mathrm{M}$ ethacridine, no colony was formed in FTC133 and SW1736 cells.

Ethacridine did not mediate cell cycle arrest. PARG and other poly(ADP-ribose) polymerases regulate various mitotic functions, including centrosome function, mitotic spindle assembly, and checkpoints (15). Given that ethacridine is a PARG inhibitor, we reason that the inhibitory effects of ethacridine may result from cell cycle arrest induced by ethacridine. We analyzed the cell cycle distribution in FTC133 and SW1736 cells, and however, there was no difference in the cell cycle distribution following the treatment with ethacridine (Figure 3). 

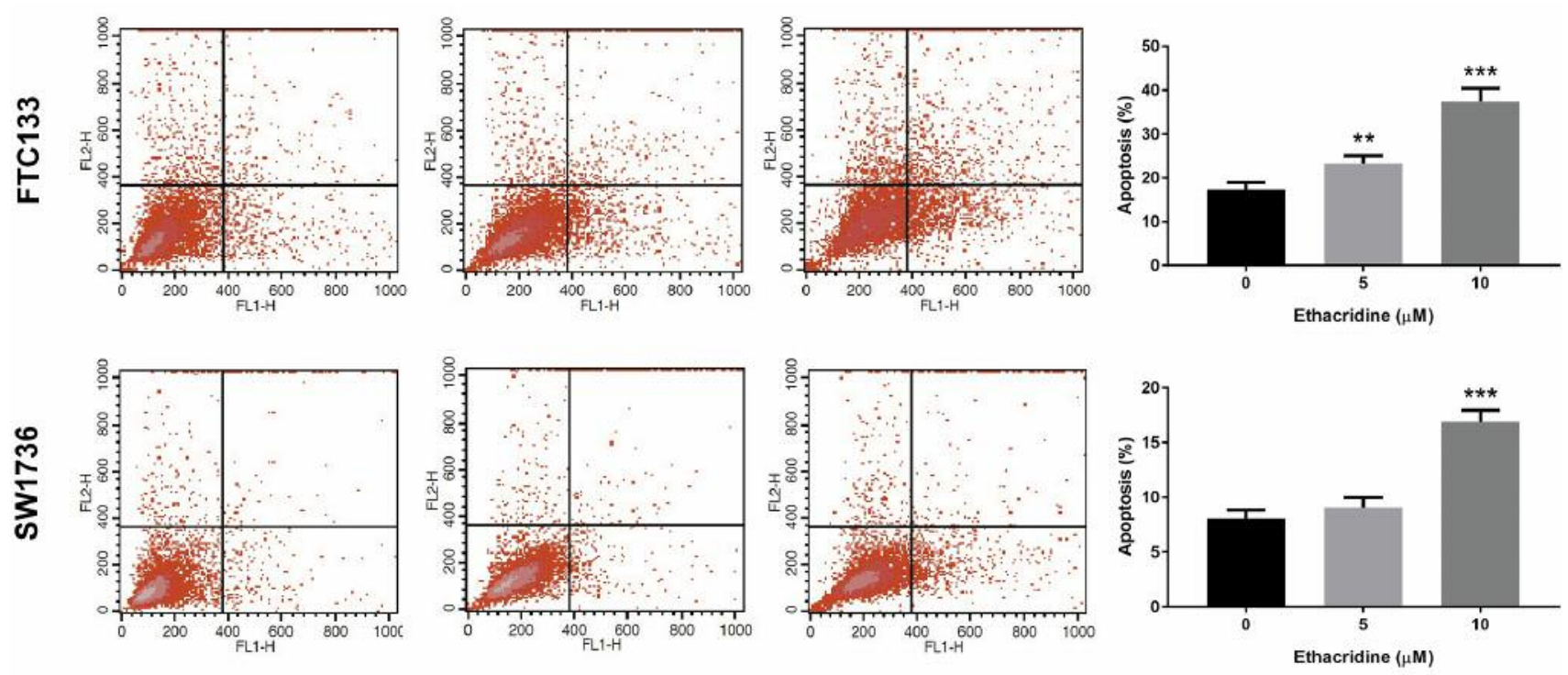

Figure 4. Effects of ethacridine on apoptosis in thyroid cancer cells. FTC133 and SW1736 cells were treated with ethacridine (0 to $10 \mu M)$ for 24 to 48 h. Apoptotic cells were determined using flow cytometry. $* * p<0.01, *^{* *} p<0.001$ versus control.
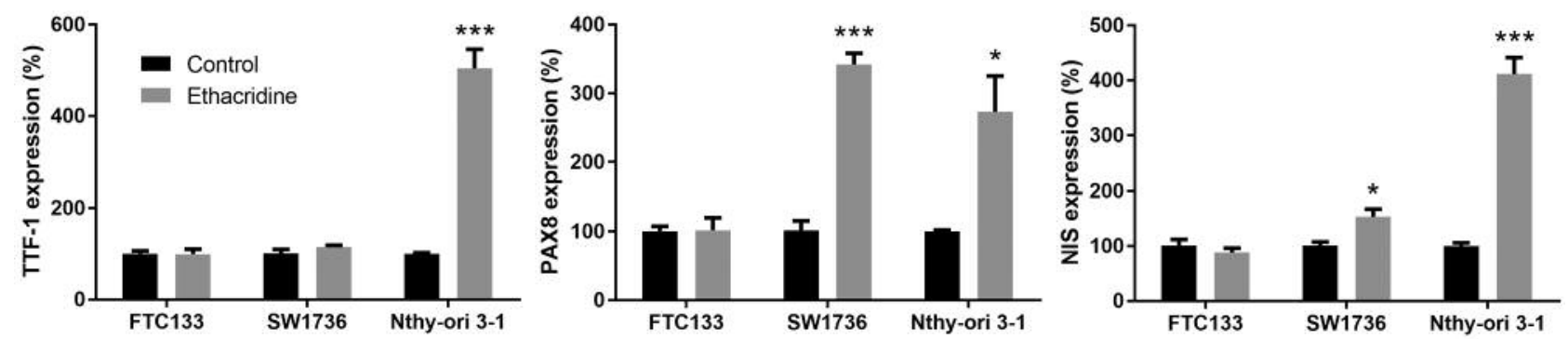

Figure 5. Effects of ethacridine on mRNA expression of TTF-1, PAX8, and NIS. Thyroid cancer cells (FTC133 and SW1736) and thyroid follicular epithelial cells (Nthy-ori 3-1) were treated with ethacridine (10 $\mu \mathrm{M})$ for $48 \mathrm{~h}$. The mRNA expression was determined using real-time quantitative polymerase chain reaction. $* p<0.05, * * * p<0.001$ versus control.

Ethacridine induced apoptosis of thyroid cancer cells. We hypothesize that apoptosis may account for the reduced cell viability following ethacridine treatment in thyroid cancer cells. The bivariate annexin V-FITC/PI analyses demonstrated that the percentage of apoptotic cells progressively increased following the treatment with ethacridine in both FTC133 and SW 1736 cells (ANOVA $p<0.001$ in both cell lines; Figure 4), indicating that apoptotic cell death plays a role in the reduced cell viability in thyroid cancer cells.

Ethacridine up-regulated thyroid transcription factors in Nthy-ori 3-1 cells. A previous study demonstrated that ethacridine may direct thyroid differentiation from human embryonic stem cells (6). Therefore, we further examined the expressions of TTF-1, PAX8, and NIS in the three cell lines (FTC133, SW1736, and Nthy-ori 3-1) following ethacridine treatment. Interestingly, a significant up-regulation of
TTF-1, PAX8, and NIS was observed in Nthy-ori 3-1 cells (fold change 5.04, 2.73, and 4.12 for TTF-1, PAX8, and NIS, respectively; $p$-values were $<0.001,0.03$, and $<0.001$, respectively; Figure 5). SW1736 cells exhibited a 3.41-fold increase in the PAX8 expression $(p<0.001)$ and a 1.53 -fold increase in the NIS expression $(p=0.026)$. However, there was no significant change in thyroid transcription factors in FTC133 cells. Taken together, the thyroid differentiationpromoting effect of ethacridine appears limited to a subset of normal and transformed thyroid epithelial cells.

\section{Discussion}

Radioactive iodine is the most effective therapy for patients with residual or metastatic thyroid cancer after surgery. An important mechanism of radioiodine refractoriness is the reduced expression or improper localization of NIS, particularly 
in BRAF-mutant thyroid cancers (16). Iodine resensitization is often considered the holy grail in the management of thyroid cancer. However, the results of previous attempts with retinoids or the PAX8-PPAR $\gamma$ agonist, rosiglitazone, are not promising (17). Recently, the use of MEK or BRAF inhibitors showed a partial response to restored radioactive iodine uptake.

Ethacridine can reduce the phosphorylation of TAZ and thus activate TAZ and Yes-associated protein-1 (YAP1) (18). TAZ and YAP have been found to preserve stemness properties (proliferation and self-renewal) of stem and progenitor cells (19). Notably, we found that ethacridine significantly upregulated the NIS expression in SW1736 and Nthy-ori 3-1 cells, although the phenomenon was more prominent in the normal Nthy-ori 3-1 cells. The SW1736 cell line is derived from anaplastic thyroid cancer and harbors BRAF V600E mutation (20). It would be interesting to validate whether other BRAF-mutant thyroid cancer cell lines have similar findings.

Speculatively, TAZ activation may enhance tumor growth and drug resistance. Actin stress fiber formation and mechanodependent YAP/TAZ activation conferred BRAF inhibitor resistance in melanoma cells (21). Overexpression of TAZ has been reported in papillary thyroid cancer (22). In this regard, we found that ethacridine induced apoptosis and suppressed cell growth in all tested cell lines. A plausible explanation is that ethacridine also inhibits PARG activity (23). PARG can hydrolyze poly(ADP-ribose) to ADP-ribose and generate ATP (24). Furthermore, PARG participates in a number of biological processes, including DNA damage repair pathways and chromatin dynamics (25). The dual mechanism makes ethacridine an attractive agent for treating thyroid cancer.

In conclusion, ethacridine suppressed viability and clonogenicity of thyroid cancer cells. It did not affect cell cycle distribution but induced apoptosis in a dose-dependent manner. It was also demonstrated that ethacridine up-regulated the NIS in a subset of thyroid follicular cells. These findings highlight the unique properties and therapeutic potential of ethacridine in thyroid cancer. Ethacridine exerts both apoptosis-inducing and redifferentiation effects on thyroid cancer cells, that can promote growth inhibition and radioiodine sensitization in patients who are not responsive to standard treatments. Nonetheless, the redifferentiation ability was not observed in all cell lines. The efficacy should be prudently evaluated in preclinical animal models, and the cross-talk between TAZ activity and the mitogen-activated protein kinase pathway deserves further investigation.

\section{Conflicts of Interest}

The Authors declare no competing interests.

\section{Authors' Contributions}

Huang and Cheng conceived the study, designed and carried out the experiments, and wrote the manuscript. Lee helped in the conception of the studies and critiqued the manuscript. Li assisted in carrying out the experiments and critiqued the manuscript.

\section{Acknowledgements}

This work was supported by research grants from the Ministry of Science and Technology of Taiwan (MOST-106-2314-B-715-008MY3) and Mackay Medical College (1071B24). The funders had no role in study design, data collection and analysis, decision to publish, or preparation of the manuscript.

\section{References}

1 Lim H, Devesa SS, Sosa JA, Check D and Kitahara CM: Trends in thyroid cancer incidence and mortality in the United States, 1974-2013. JAMA 317: 1338-1348, 2017. PMID: 28362912. DOI: $10.1001 /$ jama.2017.2719

2 Su DH, Chang SH and Chang TC: The impact of locoregional recurrences and distant metastases on the survival of patients with papillary thyroid carcinoma. Clin Endocrinol (Oxf) 82: 286-294, 2015. PMID: 24863061. DOI: 10.1111/cen.12511

3 Chien MN, Yang PS, Lee JJ, Wang TY, Hsu YC and Cheng SP: Recurrence-associated genes in papillary thyroid cancer: An analysis of data from The Cancer Genome Atlas. Surgery 161: 1642-1650, 2017. PMID: 28237646. DOI: 10.1016/j.surg.2016. 12.039

4 Berdelou A, Lamartina L, Klain M, Leboulleux S and Schlumberger M: Treatment of refractory thyroid cancer. Endocr Relat Cancer 25: R209-R223, 2018. PMID: 29371330. DOI: 10.1530/ERC-17-0542

5 Rotin LE, Gronda M, MacLean N, Hurren R, Wang X, Lin FH, Wrana J, Datti A, Barber DL, Minden MD, Slassi M and Schimmer AD: Ibrutinib synergizes with poly(ADP-ribose) glycohydrolase inhibitors to induce cell death in AML cells via a BTK-independent mechanism. Oncotarget 7: 2765-2779, 2016. PMID: 26624983. DOI: 10.18632/oncotarget.6409

6 Ma R, Morshed SA, Latif R and Davies TF: TAZ induction directs differentiation of thyroid follicular cells from human embryonic stem cells. Thyroid 27: 292-299, 2017. PMID: 27829313. DOI: $10.1089 /$ thy.2016.0264

7 Hou S, Chen Q, Zhang L, Fang A and Cheng L: Mifepristone combined with misoprostol versus intra-amniotic injection of ethacridine lactate for the termination of second trimester pregnancy: a prospective, open-label, randomized clinical trial. Eur J Obstet Gynecol Reprod Biol 151: 149-153, 2010. PMID: 20434827. DOI: 10.1016/j.ejogrb.2010.04.004

8 Lee JJ, Wang TY, Liu CL, Chien MN, Chen MJ, Hsu YC, Leung $\mathrm{CH}$ and Cheng SP: Dipeptidyl peptidase IV as a prognostic marker and therapeutic target in papillary thyroid carcinoma. $\mathrm{J}$ Clin Endocrinol Metab 102: 2930-2940, 2017. PMID: 28575350. DOI: $10.1210 /$ jc.2017-00346

9 Yang PS, Hsu YC, Lee JJ, Chen MJ, Huang SY and Cheng SP: Heme oxygenase-1 inhibitors induce cell cycle arrest and suppress tumor growth in thyroid cancer cells. Int J Mol Sci 19: E2502, 2018. PMID: 30149527. DOI: 10.3390 /ijms19092502

10 Cheng SP, Liu CL, Chen MJ, Chien MN, Leung CH, Lin CH, Hsu YC and Lee JJ: CD74 expression and its therapeutic potential in thyroid carcinoma. Endocr Relat Cancer 22: 179190, 2015. PMID: 25600560. DOI: 10.1530/ERC-14-0269 
11 Chang YC, Chen CK, Chen MJ, Lin JC, Lin CH, Huang WC, Cheng SP, Chen SN and Liu CL: Expression of $3 \beta$ hydroxysteroid dehydrogenase type 1 in breast cancer is associated with poor prognosis independent of estrogen receptor status. Ann Surg Oncol 24: 4033-4041, 2017. PMID: 28744792. DOI: $10.1245 / \mathrm{s} 10434-017-6000-6$

12 Chang YC, Hsu YC, Liu CL, Huang SY, Hu MC and Cheng SP: Local anesthetics induce apoptosis in human thyroid cancer cells through the mitogen-activated protein kinase pathway. PLoS One 9: e89563, 2014. PMID: 24586874. DOI: 10.1371/journal. pone. 0089563

13 Chang YC, Lin CH, Lin JC, Cheng SP, Chen SN and Liu CL: Inhibition of $3 \beta$-hydroxysteroid dehydrogenase type 1 suppresses interleukin-6 in breast cancer. J Surg Res 241: 8-14, 2019. PMID: 31004874. DOI: 10.1016/j.jss.2019.03.024

14 Adachi Y, Ono N, Imaizumi A, Muramatsu T, Andou T, Shimodaira Y, Nagao K, Kageyama Y, Mori M, Noguchi Y, Hashizume $\mathrm{N}$ and Nukada $\mathrm{H}$ : Plasma amino acid profile in severely frail elderly patients in Japan. Int J Gerontol 12: 290293, 2018. DOI: 10.1016/j.ijge.2018.03.003

15 Masutani $M$ and Fujimori $H$ : Poly(ADP-ribosyl)ation in carcinogenesis. Mol Aspects Med 34: 1202-1216, 2013. PMID: 23714734. DOI: 10.1016/j.mam.2013.05.003

16 Sabra MM, Dominguez JM, Grewal RK, Larson SM, Ghossein RA, Tuttle RM and Fagin JA: Clinical outcomes and molecular profile of differentiated thyroid cancers with radioiodine-avid distant metastases. J Clin Endocrinol Metab 98: E829-E836, 2013. PMID: 23533233. DOI: 10.1210/jc.2012-3933

17 Naoum GE, Morkos M, Kim B and Arafat W: Novel targeted therapies and immunotherapy for advanced thyroid cancers. Mol Cancer 17: 51, 2018. PMID: 29455653. DOI: 10.1186/s12943018-0786-0

18 Kawano S, Maruyama J, Nagashima S, Inami K, Qiu W, Iwasa H, Nakagawa K, Ishigami-Yuasa M, Kagechika H, Nishina $H$ and Hata Y: A cell-based screening for TAZ activators identifies ethacridine, a widely used antiseptic and abortifacient, as a compound that promotes dephosphorylation of TAZ and inhibits adipogenesis in C3H10T1/2 cells. J Biochem 158: 413-423, 2015. PMID: 25979969. DOI: 10.1093/jb/mvv051
19 Piccolo S, Cordenonsi M and Dupont S: Molecular pathways: YAP and TAZ take center stage in organ growth and tumorigenesis. Clin Cancer Res 19: 4925-4930, 2013. PMID: 23797907. DOI: $10.1158 / 1078-0432$.CCR-12-3172

$20 \mathrm{Xu}$ X, Quiros RM, Gattuso P, Ain KB and Prinz RA: High prevalence of BRAF gene mutation in papillary thyroid carcinomas and thyroid tumor cell lines. Cancer Res 63: 45614567, 2003. PMID: 12907632.

$21 \mathrm{Kim}$ MH, Kim J, Hong H, Lee SH, Lee JK, Jung E and Kim J: Actin remodeling confers BRAF inhibitor resistance to melanoma cells through YAP/TAZ activation. EMBO J 35: 462478, 2016. PMID: 26668268. DOI: 10.15252/embj.201592081

22 de Cristofaro T, Di Palma T, Ferraro A, Corrado A, Lucci V, Franco $\mathrm{R}$, Fusco A and Zannini M: TAZ/WWTR1 is overexpressed in papillary thyroid carcinoma. Eur J Cancer 47: 926-933, 2011. PMID: 21131195. DOI: 10.1016/j.ejca.2010. 11.008

23 Tavassoli M, Tavassoli MH and Shall S: Effect of DNA intercalators on poly(ADP-ribose) glycohydrolase activity. Biochim Biophys Acta 827: 228-234, 1985. PMID: 3838253. DOI: $10.1016 / 0167-4838(85) 90207-9$

24 Wright RH, Lioutas A, Le Dily F, Soronellas D, Pohl A, Bonet J, Nacht AS, Samino S, Font-Mateu J, Vicent GP, Wierer M, Trabado MA, Schelhorn C, Carolis C, Macias MJ, Yanes O, Oliva B and Beato M: ADP-ribose-derived nuclear ATP synthesis by NUDIX 5 is required for chromatin remodeling. Science 352: 1221-1225, 2016. PMID: 27257257. DOI: 10.1126/science.aad9335

25 Feng X and Koh DW: Roles of poly(ADP-ribose) glycohydrolase in DNA damage and apoptosis. Int Rev Cell Mol Biol 304: 227281, 2013. PMID: 23809438. DOI: 10.1016/ B978-0-12-4076969.00005-1 